2018-04

\title{
An integrated approach to assess the impacts of zinc pyrithione at different levels of biological organization in marine mussels.
}

Dallas, LJ

http://hdl.handle.net/10026.1/10858

10.1016/j.chemosphere.2017.12.144

Chemosphere

Elsevier

All content in PEARL is protected by copyright law. Author manuscripts are made available in accordance with publisher policies. Please cite only the published version using the details provided on the item record or document. In the absence of an open licence (e.g. Creative Commons), permissions for further reuse of content should be sought from the publisher or author. 


\section{An integrated approach to assess the impacts}

\section{of zinc pyrithione at different levels of biological}

Lorna J. Dallas, ${ }^{\dagger}$ Andrew Turner, ${ }^{*},{ }^{\Uparrow}$ Tim P. Bean, ${ }^{\ddagger}$ Brett P. Lyons, ${ }^{\ddagger}$ and

Awadhesh N. Jha ${ }^{\dagger}$

†School of Biological and Marine Sciences, University of Plymouth, Plymouth, UK $\ddagger$ Centre for Environment, Fisheries and Aquaculture Science, Weymouth, UK \School of Geography, Earth \& Environmental Sciences, University of

Plymouth, Plymouth, UK

E-mail: aturner@plymouth.ac.uk

Accepted 22 December 2017 Available online 27 December 2017 https://doi.org/10.1016/j.chemosphere.2017.12.144 


\begin{abstract}
The mechanisms of sublethal toxicity of the antifouling biocide, zinc pyrithione (ZnPT), have not been well-studied. This investigation demonstrates that 14-d sublethal exposure to $\mathrm{ZnPT}$ ( 0.2 or $2 \mu \mathrm{M}$, alongside inorganic $\mathrm{Zn}$ and sea water controls) is genotoxic to mussel haemocytes but suggests that this is not caused by oxidative DNA damage as no significant induction of oxidised purines was detected by Fpgmodified comet assay. More ecologically relevant endpoints, including decreased clearance rate $(\mathrm{CR})$, cessation of attachment and decreased tolerance of stress on stress (SoS), also showed significant response to ZnPT exposure. Our integrated approach was underpinned by molecular analyses (qRT-PCR of stress-related genes, 2D gel electrophoresis of proteins) that indicated ZnPT causes a decrease in phosphoenolpyruvate carboxykinase (PEPCK) expression in mussel digestive glands, and that metallothionein genes are upregulated; PEPCK downregulation suggests that altered energy metabolism may also be related to the effects of ZnPT. Significant relationships were found between \% tail DNA (comet assay) and all higher level responses (CR, attachment, SoS) in addition to PEPCK expression. Principal component analyses suggested that expression of selected genes described more variability within groups whereas \% tail DNA reflected different $\mathrm{ZnPT}$ concentrations.
\end{abstract}

Keywords: zinc pyrithione; sublethal toxicity; marine mussels; genotoxicity; DNA damage

\title{
1. Introduction
}

Zinc pyrithione (ZnPT, $\left.317.70 \mathrm{~g} \mathrm{~mol}^{-1}\right)$, an organic complex with two pyrithione ligands chelated to $\mathrm{Zn}^{2+}$, is used as a booster biocide in many copper-based antifouling paints (AFPs). Its role in such products is to increase broad-spectrum efficacy via antifungal action (Thomas et al., 2000), which also makes it ideal for use in outdoor paints for resistance to mould. ZnPT also has a variety of household and medical uses (for example, it is used in the treatment of psoriasis and is the only active ingredient in medicated anti-dandruff shampoos; Reeder et al., 2011a) resulting in multiple, additional sources from which ZnPT can enter the environment.

Although $\mathrm{ZnPT}$ is moderately hydrophobic $\left(\log \mathrm{K}_{\mathrm{OW}}=0.93\right.$ at $25^{\circ} \mathrm{C}$, solubility in 
81 water $=8 \mathrm{mg} \mathrm{L}^{-1}$ at $20^{\circ} \mathrm{C}$ ) and has the potential to accumulate in sediments, it is favoured over many other booster biocides because it can degrade relatively quickly when exposed to UV light (Price and Readman, 2013). Although there are uncertainties about the kinetics of ZnPT photo-degradation in sea water, its degradation products and the mechanisms by which it adsorbs to sediments (Maraldo and Dahllof, 2004; Turley et al., 2005; Bones et al., 2006), it is clear that the compound has potential to cause detrimental effects in aquatic species at concentrations typically encountered in environments where boating activities occur (up to $100 \mathrm{nM}$; Mackie et al., 2004; Madsen et al., 2000). For example, EC50 values for developmental abnormalities in zebrafish and medaka are 28 and $15 \mathrm{nM}$, respectively (Goka, 1999), and embryo toxicity is also reported in sea urchins (EC50 = $7.7 \mathrm{nM})$ and mussels (M. edulis, EC50 = $8 \mathrm{nM}$ ) (Bellas et al., 2005). Growth of diatoms is significantly reduced by as little as $5.9 \mathrm{nM}$ ZnPT over $96 \mathrm{~h}$ (Bao et al., 2008), while cultured ascidian haemocytes show compromised immunity after exposure to $\leq 0.5$ $\mu \mathrm{M}$ ZnPT (Cima and Ballarin, 2015) and treatment of paddy fields with ZnPT antidandruff shampoo decreased growth in juvenile medaka (Sánchez-Bayo and Goka, 2005). Recently, Marcheselli et al. (2013) demonstrated that ZnPT induced genotoxicity in marine mussels using the lethal-effect TUNEL assay. Thus, after 7-d exposure, adult Mytilus galloprovincialis showed increased DNA fragmentation and induced heat shock protein expression at ZnPT concentrations of 0.2 and $0.4 \mu \mathrm{M}$, with the higher concentration also causing a reduction in anoxia tolerance.

Despite these observations, there are still many unanswered mechanistic questions regarding $\mathrm{ZnPT}$ toxicity to aquatic biota, including mussels as ecologically important bioindicator species (Dallas et al., 2016). Furthermore, no study has attempted to connect alterations in genomic integrity with changes in protein expression by looking at intermediate processes such as transcriptional expression of relevant genes. In this context, we exposed adult M. galloprovincialis to ZnPT over a two-week time period to examine the effects of ZnPT across several levels of biological organization in the mussel. This included assessing the potential induction of oxidative DNA damage (Fpg-modified comet assay) and linking changes in genomic integrity throughout the mussel with transcriptional and protein expression (qRT-PCR and 2D gel electrophoresis, respectively) and with 
changes to higher level, more ecologically relevant responses, including clearance rate $[\mathrm{CR}]$ and attachment.. Where appropriate, observed biological responses were analysed using Principal Component Analysis (PCA) and Cluster analyses which effectively integrate multidimensional biomarker data into a more readily interpretable two dimensional format.

\section{Methods and experimental design}

\subsection{Reagents and mussel collection and maintenance}

Adult M. galloprovincialis $(48.03 \pm 2.43 \mathrm{~mm}$ ) were collected from Trebarwith Strand $\left(50^{\circ} 38^{\prime} 40^{\prime \prime} \mathrm{N}, 4^{\circ} 45^{\prime} 44^{\prime \prime} \mathrm{W}\right)$, a reference site remote from significant boating activity, and maintained in the laboratory as previously described (Dallas et al., 2013; Banni et al., 2017). Sea water used in the exposures was sourced from Plymouth Sound, stored on site and filtered on line $(<10 \mu \mathrm{m})$. Measured Cu concentrations $(<10 \mu \mathrm{g}$ $\mathrm{L}^{-1}$ ) were considerably less than added $\mathrm{Zn}$ concentrations (see below), ensuring that significant $\mathrm{Cu}(\mathrm{II})-\mathrm{Zn}$ transchelation of the pyrithione ion (PT-) was unlikely (Holmes and Turner, 2009).

Unless otherwise stated, all reagents used in the exposures and for sample processing and analysis were purchased from Sigma-Aldrich Ltd (Gillingham, UK). Ultrapure water was obtained using a Milli-Q RG (Merck Millipore, Billerica, MA, USA) or Elga Purelab Option system (Elga LabWater, Marlow, UK) and had a resistivity of $>18.2 \mathrm{M} \Omega \mathrm{cm}^{-1}$ at $25^{\circ} \mathrm{C}$.

\subsection{Exposure scenario and determination of higher level responses}

Concentrations used were based on acute range-finding exposures that compared $\mathrm{ZnPT}$ to $\mathrm{ZnCl}_{2}$ and the pyrithione ion (as $\mathrm{NaPT}$ ) at equimolar concentrations of $\mathrm{Zn}$ or PT and between 0.20 and $16.20 \mu \mathrm{M}$. These produced a 96-h LC50 for $M$. galloprovincialis of $14.50 \pm 1.45 \mu \mathrm{M}$ for PT as ZnPT ( $50 \%$ mortality not achieved for the other treatments), 7-d LC50s of $24.58 \pm 1.57 \mu \mathrm{M}$ for PT as NaPT and $8.94 \pm 1.30$ $\mu \mathrm{M}$ for PT as ZnPT, and 14-d LC50s of $2.54 \pm 1.32$ (as NaPT) and $2.97 \pm 1.36 \mu \mathrm{M}$ 
148 (as ZnPT), with 50 \% mortality not achieved for inorganic Zn (Fig. S1). Degradation 149 of ZnPT into inorganic Zn was also assessed under our experimental conditions by 150 retention and subsequent $3 \mathrm{ml} \mathrm{min}^{-1}$ methanol elution of $\mathrm{Zn}$ on conditioned octadecyl silane (C18) columns (15 mL; Chromabond, Macherey Nagel GmbH, Düren, Germany) (Holmes and Turner, 2009) (Fig. S2 A, S2 B).

Depurated (28 d) and acclimatized (48 h) M. galloprovincialis $(n=16)$ were exposed for $14 \mathrm{~d}$ and under a 12:12 h photoperiod to $0.2 \mu \mathrm{M} \mathrm{ZnPT}$ (low), $2 \mu \mathrm{M}$ ZnPT (high), 2 $\mu \mathrm{M} \mathrm{ZnCl} 2$ (inorganic) and no added $\mathrm{Zn}$ (control) in triplicate and in pre-washed plastic tanks containing $20 \mathrm{~L}$ of sea water (salinity $31.82 \pm 0.34$, $\mathrm{pH} 8.16 \pm 0.21$, dissolved oxygen $90.02 \pm 2.84 \%$ and temperature $15.88 \pm 0.52 \circ \mathrm{C})$. ZnPT concentrations were either chronic $(<10 \%$ of $14-d$ LC50) or acute $(67 \%$ of $14-d$ LC50) as determined by the range-finding experiment described above. As the degradation of ZnPT approached $80 \%$ at $48 \mathrm{~h}$ (Fig. S2 C), full water changes were performed every $2 \mathrm{~d}$ with replenishment of $\mathrm{ZnPT}$. Mussels were fed $2 \mathrm{~h}$ prior to water changes with Isochrysis galbana $\left(\sim 1.0^{5} \times 10^{6}\right.$ cells $\left.\mathrm{mL}^{-1}\right)$, and during changes on days 4, 6 and 12 (i.e. those closest to the sampling days), mussel attachment was recorded where adherence to the interior surface or to other mussels was evident when the emptied tank was tilted $45^{\circ}$. Clearance rate was determined for nine mussels per treatment (and three from each replicate) on day 14, as previously described (Devos et al., 2015), and after this time period the stress on stress (SoS) test was performed in continuous anoxic conditions for a further $20 \mathrm{~d}$ (Viarengo et al., 1995). Thus, tanks were drained and remaining mussels blotted dry before being transferred to open petri dishes where they were maintained without water but in a humid environment at $15^{\circ} \mathrm{C}$. Mortality, defined as persistent opening of the valves and failure to respond when tapped, was recorded daily and subsequently used to calculate LT50 values (median lethal time for $50 \%$ mortality).

\subsection{Genotoxicity in circulating haemocytes}

After 0, 4, 7 and $14 \mathrm{~d}$, haemolymph was extracted from nine mussels per treatment, and stored on ice pending assay, whilst $5 \mathrm{~mm}^{2}$ sections of gill and digestive gland were removed and stored at $-80{ }^{\circ} \mathrm{C}$ pending analysis. The enzyme-modified comet 
assay was performed using the haemocytes according to methods previously validated using $\mathrm{H}_{2} \mathrm{O}_{2}$ as a positive control (Dallas et al., 2013), with two slides per sample: one control containing buffer only $(40 \mathrm{mM}$ HEPES, $0.1 \mathrm{M} \mathrm{KCl}, 0.5 \mathrm{mM}$ EDTA, $0.20 \mathrm{mg} \mathrm{mL}^{-1} \mathrm{BSA}, \mathrm{pH} 8.0$ ) and one with the bacterial enzyme, formamidopyrimidine glycosylase (Fpg), to detect oxidised purine and pyrimidine bases. Prior to the performance of the comet assay, cell viability was checked using Eosin $Y$ stain and was found be $>80 \%$ for all treatments (data not shown). The micronucleus ( $\mathrm{MN}$ ) assay was performed on haemocytes as also described previously (Dallas et al., 2013) with 1000 cells scored on each coded and randomized slide.

\subsection{Alterations in transcriptional expression of candidate genes}

Total RNA was isolated from gill and digestive gland using the RNeasy mini kit (Qiagen Ltd, UK). Two $\mu \mathrm{g}$ from samples with OD260:OD280 > 1.95 and crisp bands was used for reverse transcription with M-MLV reverse transcriptase and random primers (Promega Corporation, USA). Real-time- (q-)PCR was performed on samples in duplicate (Applied Biosystems Step-One Plus RT-PCR system, StepOne Software v2.2.2) in reactions containing 7.5 $\mu \mathrm{L}$ SYBR Green Jumpstart Taq ReadyMix, $0.2 \mu \mathrm{M}$ forward and reverse primers (as detailed in Table S1), $4.44 \mu \mathrm{L}$ ultrapure water and $3 \mu \mathrm{L}$ template cDNA. Initial denaturation was at $95^{\circ} \mathrm{C}$ for $2 \mathrm{~min}$, followed by 40 cycles of $95^{\circ} \mathrm{C}$ for $15 \mathrm{~s}$ and $60^{\circ} \mathrm{C}$ for $1 \mathrm{~min}$, plus a melt curve to verify PCR-product purity. Relative expression ratio (RER) of 3 genes ( $m t 10, m t 20$ and $h s p 70$ ) was quantified using REST 2009 (v2.0.13; Qiagen Ltd) from PCR efficiency (measured using LinRegPCR) and threshold cycle $\left(C_{q}\right)$, relative to the reference genes atub (alpha tubulin) and ef1 (elongation factor 1) with control samples as calibrators (Pfaffl et al., 2002; Ramakers et al., 2003). Both reference genes showed low variability across samples $(C q$ atub $=20.45 \pm 1.26$, ef1 $=18.01 \pm$ 1.01).

\subsection{Alterations in protein expression}

Digestive glands from three mussels per exposure tank were pooled and homogenised with four parts homogenisation buffer (10 mM Tris- $\mathrm{HCl}, 0.5 \mathrm{M}$ sucrose, 
$0.15 \mathrm{M} \mathrm{KCl}, 1 \mathrm{mM}$ EDTA, $1 \mathrm{mM}$ PMSF) to provide sufficient protein and reduce interindividual variation (Karp and Lilley, 2005). Samples were prepared for 2D gel electrophoresis (2DGE) using methods of Schmidt et al. (2003). Briefly, total protein was extracted with TCA-acetone, rehydrated and loaded onto a $7 \mathrm{~cm}$ IPG strip overnight ( $\mathrm{pH}$ 3-10; GE Healthcare). Iso-electric focusing was performed using a Protean IEF cell (Bio-Rad) at $300 \mathrm{~V}$ for $3 \mathrm{~h}, 1000 \mathrm{~V}$ for $6 \mathrm{~h}$ and $8000 \mathrm{~V}$ for $3 \mathrm{~h}$, followed by $8000 \mathrm{~V}$ for $20 \mathrm{kVh}$ and hold at $500 \mathrm{~V}$. Strips were equilibrated firstly with $2 \%$ DTT and secondly with $2.5 \%$ iodoacetamide. After transfer of strips to $12 \%$ polyacrylamide gels (Mini-PROTEAN TGX, Bio-Rad), electrophoresis was carried out at $90 \mathrm{~V}$ for $1 \mathrm{~h}$, followed by $120 \mathrm{~V}$ for $30 \mathrm{~min}$ (in $0.25 \mathrm{M}$ Tris, $1.92 \mathrm{M}$ glycine, 0.03 M SDS). Gels were stained with 0.2\% Coomassie brilliant blue (R-250 in 30\% methanol, $10 \%$ acetic acid) for $1 \mathrm{~h}$, destained overnight (40\% methanol, $10 \%$ acetic acid) and visualised using a Gel Doc XR+ (Bio-Rad).

Spots of interest (i.e. those not evident in the control) were excised using sterile razor blades, dried and sent for identification (Mass Spectrometry Unit, Instituto de Tecnologia Qumica e Biolgica, Universidade Nova de Lisboa). After in-gel tryptic digestion, extracted peptides were loaded onto a R2 micro column (RP-C18 equivalent), desalted, concentrated, and eluted directly onto a MALDI plate using $\alpha$ cyano-4-hydroxycinnamic acid as the matrix solution in $50 \%$ acetonitrile and $5 \%$ formic acid. Mass spectra were acquired in positive reflectron MS and MS/MS modes using a 4800plus MALDI TOF/TOF analyser with an exclusion list of trypsin autolysis peaks (842.51, 1045.56, 2211.11 and 2225). Resulting spectra were analysed in combined mode using the Mascot search engine and NCBI database (restricted to $50 \mathrm{ppm}$ peptide mass tolerance with no taxonomy restrictions).

\subsection{Statistical analysis}

Statistics were performed in R (i386, v2.15.2; www.R-project.org) and 2DGE data were analysed using Progenesis Samespots software (v4.5.4325.32621; Nonlinear Dynamics Ltd, UK). Two-way ANOVA was undertaken on micronuclei data, after square root transformation, and comet assay data (as medians for each slide), with LC50 values determined by probit analysis and survival curves and lethal time to $50 \%$ mortality (LT50) generated according to Kaplan-Meier and compared by log- 
rank test. PCA ('prcomp' in R) and Cluster Analysis was performed for the six

250 biomarkers common to samples from days 4 and 14 (i.e. $C_{q}$ for $h s p 70, m t 20$ and $m t 10 ; \%$ tail DNA [buffer]; \% tail DNA [Fpg]; MN/1000 cells). Proteomic results and higher level responses were excluded from PCA due to pooling/non-paired samples, but relationships between these parameters were examined by generating Pearson's moment correlation coefficients.

\section{Results and discussion}

\subsection{Higher level responses}

Equimolar concentrations of $\mathrm{PT}$ in both $\mathrm{ZnPT}$ and $\mathrm{NaPT}$ induced similar mortality to adult M. galloprovincialis after exposure for $14 \mathrm{~d}$ (Fig. S1), suggesting that PT- ions are largely responsible for the effect. However, the fact that ZnPT was notably more toxic than NaPT after 4-d exposure suggests the complex as a whole has a higher acute toxicity, possibly due to its greater hydrophobicity and propensity to accumulate than the PT- ion alone.

Control mussels showed increasing attachment with time, peaking at $100 \%$ for the sea water control and $\sim 98 \%$ for the inorganic $\mathrm{Zn}$ treatment (Fig. 1A). In contrast, exposure to both low and high concentrations of $\mathrm{ZnPT}$ significantly reduced attachment at all time points compared to the control or inorganic $\mathrm{Zn}(p<0.0001)$, and never exceeded $5 \%$ throughout the time course. This effect may be the result of a generalised stress response that causes a reduction in the capacity for byssus production (Babarro et al., 2008) or a specific chemical interaction effected between $\mathrm{ZnPT}$ or $\mathrm{PT}^{-}$and byssus proteins. Regardless of the cause, these observations suggest that $\mathrm{ZnPT}$ is an effective repellant in antifouling formulations for hard-fouling organisms.

Clearance rate was also affected by $\mathrm{ZnPT}$, with a reduction from $>1.75 \mathrm{~L} \mathrm{~h}^{-1}$ in the control and inorganic $\mathrm{Zn}$ exposure to $<0.3 \mathrm{~L} \mathrm{~h}^{-1}$ at both concentrations of the complex tested (Fig. 1B). The magnitude of this decrease is comparable to that observed for mussels exposed to 18 - $56 \mu \mathrm{g} \mathrm{L}{ }^{-1} \mathrm{Cu}$ for $5 \mathrm{~d}$ (Al-Subiai et al., 2011), 32 $\mathrm{mg} \mathrm{L}^{-1}$ methyl methanesulfonate for up to $7 \mathrm{~d}$ (Canty et al., 2009) and $56 \mu \mathrm{g} \mathrm{L}^{-1}$ benzo( $\alpha$ )pyrene for $12 \mathrm{~d}$ (Di et al., 2011), and is in excess of that reported for 14-d 
exposure to branched alkyl benzenes from crude oil (Scarlett et al., 2008) and 3-d exposure to C60 fullerene nanoparticles (AI-Subiai et al., 2012). Reduced filtration in mussels causes both decreased gas exchange at the gills and reduced food intake (Bayne, 1976), and either of these parameters could have significant consequences for the energy stores that result in weakened anoxia tolerance (SoS).

During the SoS test, mussels exposed to the control or inorganic Zn declined steadily after 8 - $10 \mathrm{~d}$ (Fig. 1C), with similar LT50 values defining the two curves (14.00 \pm 0.58 and $14.00 \pm 0.55$, respectively). In contrast, mussels treated with either concentration of ZnPT declined rapidly between 3 and $6 \mathrm{~d}$ and reached total mortality earlier, with LT50 values for 0.2 and $2 \mu \mathrm{M}$ ZnPT that were significantly lower than the controls $(6.00 \pm 0.40$ and $6.00 \pm 0.34$, respectively; $p<0.0001)$. Our LT50 values are higher than those reported by Marcheselli et al. for $M$. galloprovincialis exposed to 0.4 $\mathrm{MM} \mathrm{ZnPT}$ for $7 \mathrm{~d}$ (Marcheselli et al., 2011), indicating that mussels exposed to the higher concentration of $\mathrm{ZnPT}(2 \mu \mathrm{M})$ in the current experiment survived longer under anoxic conditions. However, it must be borne in mind that control, harbour mussels in the earlier study were defined by an LT50 of $10.70 \mathrm{~d}$, suggesting that either these mussels were stressed before the exposures or there is an inherent difference between the anoxia tolerance of $M$. galloprovincialis collected for the two studies. The latter could be an artefact of the mussels' biological situation, such as current reproductive status (Bignell et al, 2008). Significant variation in LT50 values for mussels sampled from different sites and in different seasons supports this assertion (Hellou and Law, 2003; Koukouzika and Dimitriadis, 2005) and until natural variability is fully characterised, SoS should be reported as impact relative to control organisms. On this basis, mussels used here showed a greater decrease (-62.50\%) than those of Marcheselli et al. (2011) (-49.53\%), presumably because of the longer exposure to $\mathrm{ZnPT}$ employed in the present study.

\subsection{Genotoxicity in circulating haemocytes}

There was no significant effect of Fpg for any treatment and concurrent validation with in vitro exposure to hydrogen peroxide (Dallas et al., 2013) showed positive results. This confirmed that the Fpg enzyme had no significant effect on the chemicals tested (data not shown); for brevity, therefore, only buffer-treated data are 
shown and discussed. Concentrations of $2 \mu \mathrm{M}$ ZnPT induced significantly elevated DNA strand breaks in haemocytes at all time points compared with the control and inorganic $\mathrm{Zn}(p<0.001)$, with the lower concentration of ZnPT exhibiting elevated strand breaks on day 14 only (Fig. 2). Control mussel haemocytes showed normal levels of micronuclei ( $\sim 3$ per 1000 cells) whereas those treated with $2 \mu \mathrm{M}$ inorganic Zn exhibited a non-significant $(p>0.05)$ increase. In contrast, ZnPT caused a concentration- and time-dependent increase in micronuclei (MN; $p<0.0001$ ), with a maximum of $22.42 \mathrm{MN}$ per 1000 cells in the $2 \mu \mathrm{M}$ ZnPT exposure on day 14 (Fig. 2).

These results provide independent confirmation that $\mathrm{ZnPT}$ is genotoxic to mussels, as reported by Marcheselli et al. (2011) in gills and digestive gland using the TUNEL assay. This is, however, the first report of $\mathrm{ZnPT}$-induced sublethal genotoxicity in mussel haemocytes, which does not appear to be caused by purine oxidation (based on the enzyme-modified comet assay results). Similar results were obtained when potential genotoxicity in haemocytes were determined following exposure of mussels to nickel (Dallas et al., 2013). These studies suggest that mussel haemocytes might have some inherent limitations to express metal- or organometallic-induced oxidative damage to DNA. In this context, enzymatic repair of DNA oxidation induced by chromium (VI) in mussel gill cells have suggested that DNA repair processes could mask the oxidative damage and this could be influenced as a function of sampling time (Emmanouil et al., 2006). Results from this and earlier studies (Dallas et al., 2013) suggest that mussel haemocytes are able to maintain homoeostasis with respect to DNA oxidation but further studies involving repeated sampling would be required to shed light on the persistence of DNA oxidation. Furthermore, our results suggest good correlations between induction of DNA strand breaks (as determined by the comet assay) and cytogenetic damage (as determined by the MN assay). This is in line with many in vivo and in vitro studies reported previously (Canty et al., 2009; Dallas et al., 2013)., strengthening the case for the concomitant use of these genotoxicity endpoints.

Although Nunes et al. (2015) studied oxidative stress in the freshwater fish, Gambusia holbrooki, after exposure to $\mathrm{ZnPT}$, to our knowledge the present investigation is the first to examine such effects in a marine organism., with both studies finding no increase in catalase or glutathione-s-transferase activity effected 
by the chemical. The current comet assay results are also in agreement with in vitro data from rat cardiomyocytes, where ZnPT reduced superoxide generation and oxidative injury (as both LDH release and cell survival) after reperfusion (Kasi et al., 2011). However, the mammalian literature is somewhat contradictory in that ZnPT causes increased susceptibility to ROS-induced damage in rat thymocytes coexposed to hydrogen peroxide (Oyama et al. 2012). Furthermore, a study on human skin cells reported upregulation of metallothionein genes, commonly associated with oxidative stress (Lamore and Wondrak, 2011). The latter observation may be explained by the known metal binding capacity of metallothionein proteins, i.e. the effect may be induced by $\mathrm{Zn}$ itself rather than $\mathrm{ZnPT}$. Further research to directly quantify ROS in mussel cells (of different tissues) is recommended to elucidate the mechanisms behind the genotoxic effects of $\mathrm{ZnPT}$.

\subsection{Alterations in transcriptional expression of key genes}

Whilst many studies have been carried out to determine the toxicity of metals to mussels (Lemoine et al., 2000; Banni et al., 2007; Al-Subiai et al., 2011; Dallas et al., 2013; Varotto et al., 2013), there is limited information on their response to ZnPT or other pyrithione compounds. Although the anti-dandruff characteristics of ZnPT may result from indirect effects on skin cells (e.g. suppressed DNA synthesis; Imokawa et al., 1983), in yeast the complex exhibits specific anti-fungal activity via iron starvation or decreased iron-containing protein activity as a result of elevated intracellular $\mathrm{Cu}$ (Yasokawa et al., 2010; Reeder et al., 2011b). There are also several reports of genotoxicity and stress response induction (especially HSPs and increased p53 expression) in human skin cells exposed to ZnPT (Lamore and Wondrak, 2011; Rudolf and Cervinka, 2011; Lamore et al., 2010). The molecular approaches used here were designed to elucidate which - if any - of these potential mechanisms contribute to ZnPT-induced toxicity in marine mussels.

In the present study, qPCR efficiencies were $h s p 701.750 / 1.798, m t 101.791 / 1.830$ and $m t 201.838 / 1.846$ for gill/digestive gland of $M$. galloprovincialis. Significant changes in expression were tissue-specific and only seen in digestive gland at day 4, where all three target genes showed upregulation at the low ZnPT concentration but only $h s p 70$ and $m t 20$ showed upregulation at the high concentration (Fig. 3); in gill, 
upregulation of $h s p 70$ and $m t 20$ occurred for $2 \mu \mathrm{M}$ ZnPT at day 14 only (Fig. 3).

386 Temporal differences in $h s p 70$ and $m t 20$ expression observed between the gill and 387 digestive gland may be linked to time-dependent variations in the location of $\mathrm{ZnPT}$ 388 accumulation by mussels; for example, Marcheselli et al. (2010b) report increased accumulation in digestive gland compared with gill of $M$. galloprovincialis after $\geq 2 \mathrm{~d}$ exposure to $1.5 \mu \mathrm{M} \mathrm{ZnPT}$. Regarding HSPs, both the present study and that of Marcheselli et al.(2011) have identified these genes as components of the ZnPT response in M. galloprovincialis. Furthermore, studies in human skin cells have reported upregulation of HSPs and metalliothionein genes after ZnPT treatment, suggesting that these genes and their toxic responses might be highly conserved (Lamore and Wondrak, 2011; Lamore et al., 2010).

PCA and Cluster Analysis of the six common biomarkers showed that the first component (PC1) explained $44.1 \%$ and $59.0 \%$ of total variance at day 4 and 14 , respectively (Fig. 4B and 4C), and was mostly related to mt20 activity at day 4 but with no defining biomarker at day 14. Treatment-specific clusters were evident at both time points, but were more diffuse by day 14. However, the treatment-related clusters were more clearly separated from each other at day 14, whereas there was considerable overlap between treatments at day 4. Gene expression described more variability within groups, while genotoxic parameters distinguished between treatments. This suggests that either intra-individual variability is masking treatmentspecific effects on these genes, or that investigation of other genes (e.g. p53 and those for other DNA repair proteins) may provide a better understanding of the mechanistic aspects of the genotoxicity of ZnPT. It is well accepted that the toxicity of a chemical or environmental stressor is a cellor tissue-specific phenomenon (Jha, 2008; 2004; Di et al., 2011). In the present study, DNA damage using the comet assay was determined in the circulating lymphocytes whereas the expression of genes were determined in different tissues. While assessing the biological responses at the cellular and tissue level due to technical and tissue-specific inherent limitations, it is not always possible to apply the same assay across the biological samples obtained. For example, circulating lymphocytes which could be obtained in small amounts from mussels are ideal for the analysis of DNA damage using the comet assay whilst other tissues are ideal for 
gene expression analyses. For the application of comet assay, it is a prerequisite to obtain a single cell suspension, which is not necessary for circulating haemocytes. On the other hand, application of the comet assay on solid tissues (e.g. digestive glands, gills etc.) require mechanical and enzymatic treatments, which could induce DNA damage in their own right (Jha, 2008). It is also important to point out that gene expression results could give different results in different tissues (Di et al., 2011). In addition, since different tissues have different turnover rates (cell cycle durations) and metabolic properties and the fact that contaminants could induce cell cycle stage specific changes for gene expression (Di et al., 2011), it is difficult to justify selection of a particular cell or tissue type for different biological assays. In this study, therefore, we used a range of cell types and the observed biological responses were analysed using PCA and Cluster analysis to obtain a holistic picture.

\subsection{Alterations in protein expression}

Digestive gland proteins were well-separated on the gel, with minimal streaking or smearing (Fig. S3). Only spots showing significant fold change $(\geq 1.5$ and $p<0.05)$ relative to both the sea water control and inorganic $\mathrm{Zn}$ exposure were considered as ZnPT-specific effects (5 spots and all on day 4, Table 1). Two such spots were positively identified by mass spectroscopy; specifically, spot 355 was significantly homologous to a predicted protein sequence for phosphoenolpyruvate carboxykinase (PEPCK) in barley (GenBank BAK02183.1), and spot 550 was a small HSP from M. galloprovincialis (GenBank AEP02968.1). Of the remaining spots, 1 could not be identified due to low protein content (607) and the other 2 had no matching sequences, possibly due to extensive post-translational modification.

Although several studies have examined PEPCK levels in mussels in response to physical stressors like temperature and salinity (Anestis et al., 2010; Lockwood and Somero, 2011; Tomanek and Zuzow, 2010), our investigation appears to be the first to demonstrate a negative impact on PEPCK by a contaminant in a model marine organism. If decreased PEPCK protein after 4-d ZnPT exposure corresponds to decreased PEPCK activity, this could compromise the ability of mussels to cope with anoxic conditions, as seen in the SoS assay. In contrast, Widdows et al. (1982) reported increased PEPCK activity in M. galloprovincialis after $140 \mathrm{~d}$ exposure to 30 
$\mu \mathrm{g} \mathrm{L}^{-1}$ water-accommodated hydrocarbons. The discrepancies between these two responses may be attributed to a number of factors. Thus, firstly our study did not measure enzyme activity but determined expression of protein, and posttranslational modification to activate or suppress PEPCK may result in differences between expression and activity. Secondly, given that changes in PEPCK expression appeared herein at day 4 but were not evident by day 14, it is possible that temporal shifts in expression-activity patterns may have occurred in our experiment, suggesting we are observing baseline variation rather than biological effect. Thirdly, responses are often contaminant- or tissue-specific; for instance, kinetic studies of glycolytic enzymes in $M$. edulis have shown significant variation in activity between adductor muscle (catabolic tissue) and mantle (anabolic tissue) (Churchill and Livingstone, 1989).

\subsection{Environmental risk assessment and future work}

Given the detrimental effects of ZnPT on M. galloprovincialis at all levels of biological organization, it is perhaps surprising that mussels are found in abundance in many marinas where the biocide has the potential to reach levels considerably higher than in pristine waters through leaching from boat hulls and from spent antifouling waste (Holmes and Turner, 2009). It is possible, however, that mussels from environments impacted by boating have adapted to elevated $\mathrm{ZnPT}$ concentrations through some resistance mechanism or compensatory response. For instance, it is known that $M$. edulis exhibit a high adaptive capacity to the impact of a variety of metallic and lipophilic contaminants (Bakhmet et al., 2009). To this end, a useful extension to the current work would be a direct comparison of the condition and response of mussels from a reference site with those from a region where boat storage or maintenance is significant.

There are several issues that need to be addressed before the general environmental risk from ZnPT can be more accurately estimated. Regarding environmental concentrations, there exist only limited data, with a reported range in the aqueous phase (as PT) between about 2 and $100 \mathrm{nM}$ for marinas and navigation channels (Mackie et al., 2004; Madsen et al., 2000). While this range is lower than 
concentrations employed in the present study, environmental concentrations may be elevated locally by point sources and more generally in turbid or shaded sea water (e.g. under pontoons and boats) where the biocide is more persistent (Marcheselli et al., 2010b). ZnPT induces considerable physiological and behavioural effects in mussels in addition to its genotoxicity, and emphasizing the need for integrated studies that examine a wide range of effects. Also, as mussels appear to be more tolerant of ZnPT than crustaceans and polychaetes (Bao et al., 2008; Mochida et al., 2006; Marcheselli et al., 2010b), the wide-ranging effects demonstrated here also suggest a greater potential risk to other marine biota. Studying the effects of this compound in a wider range of aquatic invertebrate species is, therefore, essential. Indirectly, ZnPT has additional impacts through transchelation of $\mathrm{PT}^{-}$ions with $\mathrm{Cu}^{2+}$ (the primary ion formed during the ablation of most contemporary antifouling formulations) (Holmes and Turner, 2009; Grunnet and Dahllof, 2005). Studies suggest that CuPT is more toxic than its Zn counterpart (Bao et al., 2011) and that mixtures exhibit synergistic effects (Bao et al., 2014), but more experimental studies would be required to explore these effects in a broader context.

\section{Acknowledgements}

We wish to thank Dr William Vevers and Dr Andy Fisher (University of Plymouth) for their technical assistance and advice. We also thank Professor Michael Moore (Plymouth Marine Laboratory and University of Plymouth) for helpful discussions about the results. Financial support for this study from the European Regional Development Fund, INTERREG IVA (Grant No. 4059), is gratefully acknowledged.

\section{References}

Al-Subiai, S. N.; Moody, A. J.; Mustafa, S. A.; Jha, A. N. A multiple biomarker approach to investigate the effects of copper on the marine bivalve mollusc, Mytilus edulis. Ecotoxicology and Environmental Safety 2011, 74, 1913-20.

Al-Subiai, S. N.; Arlt, V. M.; Frickers, P. E.; Readman, J. W.; Stolpe, B.; Lead, J. R.; Moody, A. J.; Jha, A. N. Merging nano-genotoxicology with eco-genotoxicology: An integrated approach to determine interactive genotoxic and sub-lethal toxic effects of C-60 fullerenes and fluoranthene in marine mussels, Mytilus sp. Mutation ResearchGenetic Toxicology and Environmental Mutagenesis 2012, 745, 92-103. 
Anestis, A.; Pörtner, H. O.; Karagiannis, D.; Angelidis, P.; Staikou, A.; Michaelidis, B. Response of Mytilus galloprovincialis (L.) to increasing seawater temperature and to marteliosis: Metabolic and physiological parameters. Comparative Biochemistry and Physiology Part A: Molecular and Integrative Physiology 2010b, 156, 57-66.

Babarro, J. M.; Fernndez Reiriz, M. J.; Labarta, U. Secretion of byssal threads and attachment strength of Mytilus galloprovincialis: the influence of size and food availability. Journal of the Marine Biological Association of the United Kingdom 2008, 88, 783-791.

Bakhmet, I.N.,Fokina, N.N., Nefedova, Z.A., Nemova, N.N. Physiologicalbiochemical properties of blue mussel Mytilus edulis adaptation to oil contamination. Environmental Monitoring and Assessment 2009, 155, 581-591.

Bao, V. W. W.; Leung, K. M. Y.; Kwok, K. W. H.; Zhang, A. Q.; Lui, G. C. S. Synergistic toxic effects of zinc pyrithione and copper to three marine species: Implications on setting appropriate water quality criteria. Marine Pollution Bulletin 2008, 57, 616-623.

Bao, V. W. W.; Leung, K. M. Y.; Qiu, J.-W.; Lam, M. H. W. Acute toxicities of five commonly used antifouling booster biocides to selected subtropical and cosmopolitan marine species. Marine Pollution Bulletin 2011, 62, 1147-1151.

Bao, V. W. W.; Lui, G. C. S.; Leung, K. M. Y. Acute and chronic toxicities of zinc pyrithione alone and in combination with copper to the marine copepod Tigriopus japonicus. Aquatic Toxicology 2014, 157, 81-93.

Banni, M.; Dondero, F.; Jebali, J.; Guerbej, H.; Boussetta, H.; Viarengo, A. Assessment of heavy metal contamination using real-time PCR analysis of mussel metallothionein $m t 10$ and $m t 20$ expression: a validation along the Tunisian coast. Biomarkers 2007, 12, 369-383. 
555 Pacchioni, C Millino, G Lanfranchi, JW Readman, MN Moore, A Viarengo, AN Jha 556 (2017) Assessing the impact of benzo[a]pyrene on marine mussels: Application of a novel targeted low density microarray complementing classical biomarker responses.

558 PLoS ONE 12 (6): e0178460doi.org/10.1371/journl.pone.0178460

559

560 Bayne, B. Marine Mussels: Their Ecology and Physiology; Cambridge University

561 Press: Cambridge, UK, 1976.

562

563 Bellas, J.; Granmo, A.; Beiras, R. Embryotoxicity of the antifouling biocide zinc

564 pyrithione to sea urchin (Paracentrotus lividus) and mussel (Mytilus edulis). Marine

565 Pollution Bulletin 2005, 50, 1382-1385.

566

567 Bignell, J.P., Dodge, M.J., Feist, S.W., Lyons, B., Martin, P.D., Taylor, N.G.H.,

568 Stone, D., Travalent, L.; Stentiford, G.D. Mussel histopathology: effects of season, 569 disease and species. Aquatic Biology 2008, 2, 1-15.

570

571

572

Bones, J.; Thomas, K. V.; Paull, B. Improved method for the determination of zinc

573 pyrithione in environmental water samples incorporating on-line extraction and preconcentration coupled with liquid chromatography atmospheric pressure chemical ionisation mass spectrometry. Journal of Chromatography A 2006, 1132, 157-164.

576

Canty, M. N.; Hutchinson, T. H.; Brown, R. J.; Jones, M. B.; Jha, A. N. Linking 578 genotoxic responses with cytotoxic and behavioural or physiological consequences: Differential sensitivity of echinoderms (Asterias rubens) and marine molluscs (Mytilus edulis). Aquatic Toxicology 2009, 94, 68-76.

Churchill, H. M.; Livingstone, D. R. Kinetic studies of the glycolytic enzymes from the 583 mantle and posterior adductor muscle of the common mussel, Mytilus edulis L., and use of activity ratio $(\mathrm{Vm} / \mathrm{v})$ as an indicator of apparent $\mathrm{Km}$. Comparative Biochemistry and Physiology Part B: Comparative Biochemistry 1989, 94, 299-314. to organotins IV. The case of zinc pyrithione. Comparative Biochemistry and 
589 Physiology Part C: Toxicology and Pharmacology 2015, 169, 16-24.

590

591 Dallas, L. J.; Bean, T. P.; Turner, A.; Lyons, B. P.; Jha, A. N. Oxidative DNA damage 592 may not mediate Ni-induced genotoxicity in marine mussels: Assessment of 593 genotoxic biomarkers and transcriptional responses of key stress genes. Mutation

594 Research/Genetic Toxicology and Environmental Mutagenesis 2013, 754, 22-31. 595

596 Dallas, L. J.; Devos, A.; Fievet, B.; Turner, A.; Lyons, B. P.; Jha, A. N. Radiation 597 dose estimation for marine mussels following exposure to tritium: Best practice for 598 use of the ERICA tool in ecotoxicological studies. Journal of Environmental 599 Radioactivity 2016, 155/156, 1-6.

600

601 Devos, A.; Dallas, L. J.; Voiseux, C.; Lecomte-Pradines, C.; Jha, A. N.; Fivet, B.

602 Assessment of growth, genotoxic responses and expression of stress related genes

603 in the Pacific oyster Crassostrea gigas following chronic exposure to ionizing 604 radiation. Marine Pollution Bulletin 2015, 95, 688-698.

605

606 Di, Y.; Schroeder, D. C.; Highfield, A.; Readman, J. W.; Jha, A. N. Tissue-Specific

607 Expression of p53 and ras genes in response to the environmental genotoxicant 608 benzo(a)pyrene in marine mussels. Environmental Science and Technology 2011, $609 \quad 45,8974-8981$.

610

611 Emmanouil, C.; Smart, .J.; Hodges, N.J.; Chipman, J.K. Oxidative damage produced 612 by $\operatorname{Cr}(\mathrm{VI})$ and repair in mussel (Mytilus edulis L.) gill. Marine Environ Research 2006, 61362 (Suppl. 1), S292-S296.

615 Goka, K. Embryotoxicity of zinc pyrithione, an antidandruff chemical, in fish.

616 Environmental Research 1999, 81, 81-3.

617

618 Grunnet, K. S.; Dahllof, I. Environmental fate of the antifouling compound zinc 619 pyrithione in seawater. Environmental Toxicology and Chemistry 2005, 24, 3001-6. 620 621 Jha A.N. Ecotoxicological applications and significance of the comet assay. 622 Mutagenesis 2008, 23, 207-221. 
624 Jha A.N. Genotoxicological studies in aquatic organisms: an overview. Mutation

625 Research 2004, 552, 1-17.

626

627 Hellou, J.; Law, R. J. Stress on stress response of wild mussels, Mytilus edulis and 628 Mytilus trossulus, as an indicator of ecosystem health. Environmental Pollution 2003, 629 126, 407-416.

630

631 Holmes, L.; Turner, A. Leaching of hydrophobic $\mathrm{Cu}$ and $\mathrm{Zn}$ from discarded marine 632 antifouling paint residues: Evidence for transchelation of metal pyrithiones.

633 Environmental Pollution 2009, 157, 3440-3444.

634

635 Imokawa, G.; Okamoto, K. The effect of zinc pyrithione on human skin cells in vitro.

636 Journal of the Society of Cosmetic Chemists 1983, 34, 1-11.

637

638

639 Karp, N. A.; Lilley, K. S. Maximising sensitivity for detecting changes in protein

640 expression: experimental design using minimal CyDyes. Proteomics 2005, 5, 310564115.

642

643 Kasi, V.; Bodiga, S.; Kommuguri, U. N.; Sankuru, S.; Bodiga, V. L. Zinc pyrithione

644 salvages reperfusion injury by inhibiting NADPH oxidase activation in

645 cardiomyocytes. Biochemical and Biophysical Research Communications 2011, 410, $646270-275$.

648 Koukouzika, N.; Dimitriadis, V. K. Multiple biomarker comparison in Mytilus

649 galloprovincialis from the Greece coast: "Iysosomal membrane stability, neutral red

650 retention, micronucleus frequency and stress on stress". Ecotoxicology 2005, 14, $651 \quad 449-63$.

652

653 Lamore, S. D.; Wondrak, G. T. Zinc pyrithione impairs zinc homeostasis and 654 upregulates stress response gene expression in reconstructed human epidermis. 655 Biometals 2011, 24, 875-890. 
657 Lamore, S. D.; Cabello, C. M.; Wondrak, G. T. The topical antimicrobial zinc

658 pyrithione is a heat shock response inducer that causes DNA damage and PARP-

659 dependent energy crisis in human skin cells. Cell Stress and Chaperones 2010, 15,

$660 \quad 309-322$.

661

662 Lemoine, S.; Bigot, Y.; Sellos, D.; Cosson, R. P.; Laulier, M. Metallothionein isoforms

663 in Mytilus edulis (Mollusca, Bivalvia): Complementary DNA characterization and

664 quantification of expression in different organs after exposure to cadmium, zinc, and

665 copper. Marine Biotechnology 2000, 2, 195-203.

666

667 Lockwood, B. L.; Somero, G. N. Transcriptomic responses to salinity stress in

668 invasive and native blue mussels (genus Mytilus). Molecular Ecology 2011, 20, $517-$ 669529.

670

671 Mackie, D. S.; van den Berg, C. M. G.; Readman, J. W. Determination of pyrithione

672 in natural waters by cathodic stripping voltammetry. Analytica Chimica Acta 2004,

$673511,47-53$.

674

675 Madsen, T.; Gustavsson, K.; Samsœ-Petersen, L.; Simonsen, F.; Jakobsen, J.;

676 Foverskov, S.; Larsen, M. M. Ecotoxicological assessments of antifouling biocides

677 and nonbiocidal paints. Environmental Project No. 531 ; Danish Environmental

678 Protection Agency: Copenhagen, Denmark, 2000; pp 1-112.

679

680 Marcheselli, M.; Rustichelli, C.; Mauri, M. Novel antifouling agent zinc pyrithione:

681 determination, acute toxicity, and bioaccumulation in marine mussels (Mytilus

682 galloprovincialis). Environmental Toxicology and Chemistry 2010a, 29, 2583-92.

683

684 Marcheselli, M.; Conzo, F.; Mauri, M.; Simonini, R. Novel antifouling agent-Zinc

685 pyrithione: Short- and long-term effects on survival and reproduction of the marine

686 polychaete Dinophilus gyrociliatus. Aquatic Toxicology 2010b, 98, 204-210.

687

688 Marcheselli, M.; Azzoni, P.; Mauri, M. Novel antifouling agent-zinc pyrithione: Stress

689 induction and genotoxicity to the marine mussel Mytilus galloprovincialis. Aquatic

690 Toxicology 2011, 102, 39-47. 
692 Maraldo, K.; Dahllof, I. Indirect estimation of degradation time for zinc pyrithione and copper pyrithione in seawater. Marine Pollution Bulletin 2004, 48, 894-901.

Mochida, K.; Ito, K.; Harino, H.; Kakuno, A.; Fujii, K. Acute toxicity of pyrithione antifouling biocides and joint toxicity with copper to red sea bream (Pagrus major) and toy shrimp (Heptacarpus futilirostris). Environmental Toxicology and Chemistry 2006, 25, 3058-3064.

700

701

702

Moon, T. W.; Johnston, I. A. Starvation and the activities of glycolytic and 703 gluconeogenic enzymes in skeletal muscles and liver of the plaice, Pleuronectes platessa. Journal of Comparative Physiology 1980, 136, 31-38.

Nunes, B.; Braga, M. R.; Campos, J. C.; Gomes, R.; Ramos, A. S.; Antunes, S. C.; 708 Correia, A. T. Ecotoxicological effect of zinc pyrithione in the freshwater fish Gambusia holbrooki. Ecotoxicology 2015, 24, 1896-905.

Oyama, T. M., Saito, M., Yonezawa, T., Okano, Y., Oyama, Y. Nanomolar concentrations of zinc pyrithione increase cell susceptibility to oxidative stress induced by hydrogen peroxide in rat thymocytes, Chemosphere, $2012,87,1316-$ 1322.

Pfaffl, M. W.; Horgan, G. W.; Dempfle, L. Relative expression software tool (REST) for group-wise comparison and statistical analysis of relative expression results in real-time PCR. Nucleic Acids Research 2002, 30 .

Price, A. R. G.; Readman, J. Late lessons from early warnings: science, precaution, innovation. EEA Report No 1/2013 ; European Environment Agency: Copenhagen, Denmark, 2013; pp 265-278.

Ramakers, C.; Ruijter, J. M.; Deprez, R. H.; Moorman, A. F. Assumption-free analysis of quantitative real-time polymerase chain reaction (PCR) data. Neuroscience Letters 2003, 339, 62-6.

Reeder, N. L.; Xu, J.; Youngquist, R. S.; Schwartz, J. R.; Rust, R. C.; Saunders, C. 
W. The antifungal mechanism of action of zinc pyrithione. British Journal of

Reeder, N. L., Kaplan, J., Xu, J., Youngquist, R. S., Wallace, J., Hu, P., Juhlin, K. D., Schwartz, J. R., Grant, R. A., Fieno, A., Nemeth, S., Reichling, T., Tiesman, J. P., Mills, T., Steinke, M., Wang, S. L., Saunders, C. W. Zinc pyrithione inhibits yeast growth through copper influx and inactivation of iron-sulfur proteins. Antimicrobial Agents and Chemotherapy 2011b, 55, 5753-5760.

Rudolf, E.; Cervinka, M. Stress responses of human dermal fibroblasts exposed to zinc pyrithione. Toxicology Letters 2011, 204, 164-173.

Sánchez-Bayo, F.; Goka, K. Unexpected effects of zinc pyrithione and imidacloprid on Japanese medaka fish (Oryzias latipes). Aquatic Toxicology 2005, 74, 285-293.

Scarlett, A.; Rowland, S. J.; Galloway, T. S.; Lewis, A. C.; Booth, A. M. Chronic sublethal effects associated with branched alkylbenzenes bioaccumulated by mussels. Environmental Toxicology and Chemistry 2008, 27, 561-567.

Schmidt, W.; Rainville, L.-C.; McEneff, G.; Sheehan, D.; Quinn, B. A proteomic evalu- ation of the effects of the pharmaceuticals diclofenac and gemfibrozil on marine mussels (Mytilus spp.): evidence for chronic sublethal effects on stressresponse proteins. Drug Testing and Analysis 2013, doi: 10.1002/dta.1463.

Thomas, K. V.; Blake, S. J.; Waldock, M. J. Antifouling paint booster biocide contamination in UK marine sediments. Marine Pollution Bulletin 2000, 40, 739-745.

Tomanek, L.; Zuzow, M. J. The proteomic response of the mussel congeners Mytilus galloprovincialis and $M$. trossulus to acute heat stress: implications for thermal tolerance limits and metabolic costs of thermal stress. Journal of Experimental Biology 2010, 213, 3559-74. 
764 Varotto, L.; Domeneghetti, S.; Rosani, U.; Manfrin, C.; Cajaraville, M. P.; Rac-

765 canelli, S.; Pallavicini, A.; Venier, P. DNA damage and transcriptional changes in the

766 gills of Mytilus galloprovincialis exposed to nanomolar doses of combined metal 767 salts (Cd, Cu, Hg). Plos One 2013, 8, e54602.

768

769 Viarengo, A.; Cannes, L.A.; Pertica, M.; Mancinelli, G.; Accomando, R.; Smaal, A.

C.; Orunesu, M. Stress on stress response: A simple monitoring tool in the assessment of a general stress syndrome in mussels. Marine Environmental Research 1995, 39, 245-248.

Widdows, J.; Bakke, T.; Bayne, B. L.; Donkin, P.; Livingstone, D. R.; Lowe, D. M.; Moore, M. N.; Evans, S. V.; Moore, S. L. Responses of Mytilus edulis on exposure to the water-accommodated fraction of North Sea oil. Marine Biology 1982, 67, 15-31.

Yasokawa, D.; Murata, S.; Iwahashi, Y.; Kitagawa, E.; Kishi, K.; Okumura, Y.; Iwahashi, $\mathrm{H}$. DNA microarray analysis suggests that zinc pyrithione causes iron starvation to the yeast Saccharomyces cerevisiae. Journal of Bioscience and 781 Bioengineering 2010, 109, 479-486.

782

783

784

785

786

787

788

789

790

791

792 

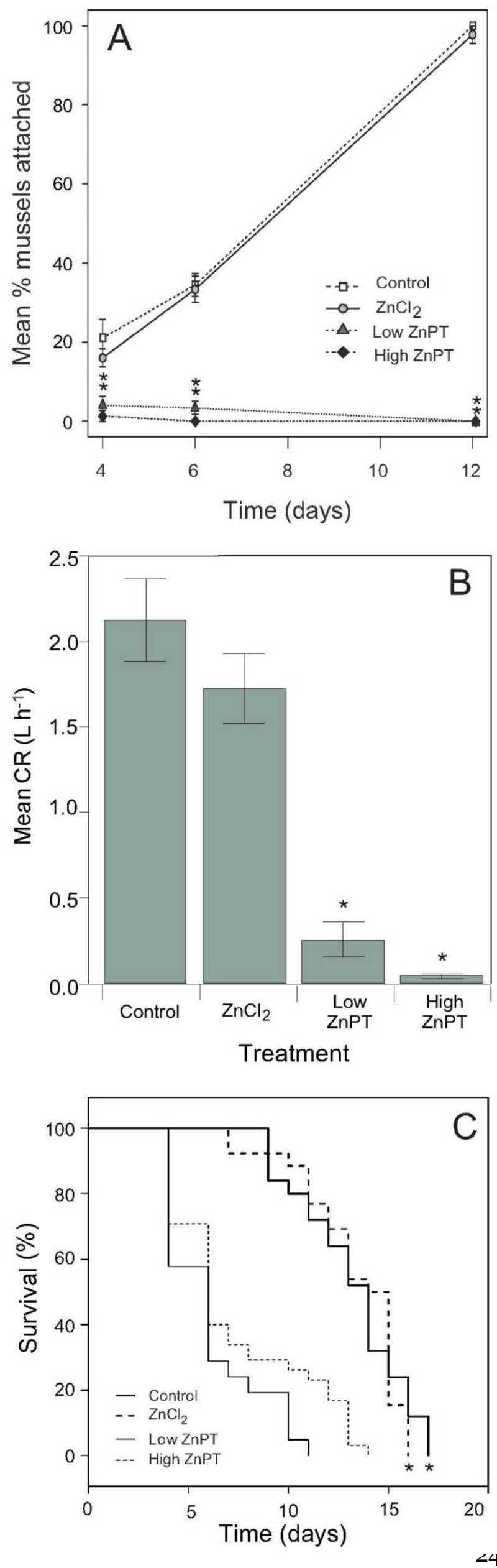
798 Figure 1: Higher level responses of M. galloprovincialis exposed to inorganic $\mathrm{Zn}$ or 799 ZnPT. (A) Percentage of mussels showing attachment during $14 \mathrm{~d}$ exposure; (B) 800 clearance rate (CR) after $14 \mathrm{~d}$ exposure; (C) survival (SoS; $n=25$ ) in anoxic 801 conditions during $20 \mathrm{~d}$ after exposure. Error bars are \pm one $S E$ and asterisks indicate 802 significant differences $(p<0.05)$ from both sea water and inorganic $\mathrm{Zn}$ treatments. 803 
804 Figure 2: Genotoxicity in M. galloprovincialis haemocytes after exposure to inorganic $805 \mathrm{Zn}$ or ZnPT for (A) 0, (B) 4, (C) 7 or (D) 14 d, and as determined by the enzyme-

806 modified comet assay (\% tail DNA; bars) and micronuclei assay (per 1000 cells;

807 black circles). Error bars are \pm one SE and asterisks indicate significant differences

$808(p<0.05)$ from both sea water and inorganic $\mathrm{Zn}$ treatments on the same day,

809 whereas daggers indicate differences from day 0.

810

811

812

813

814
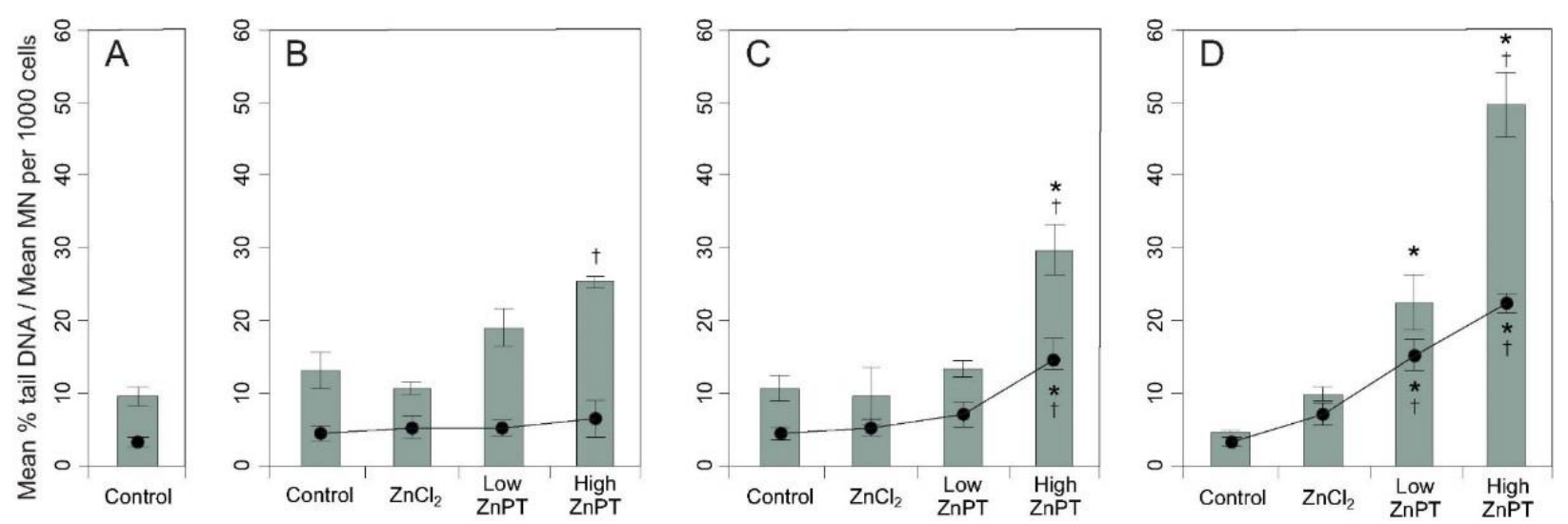

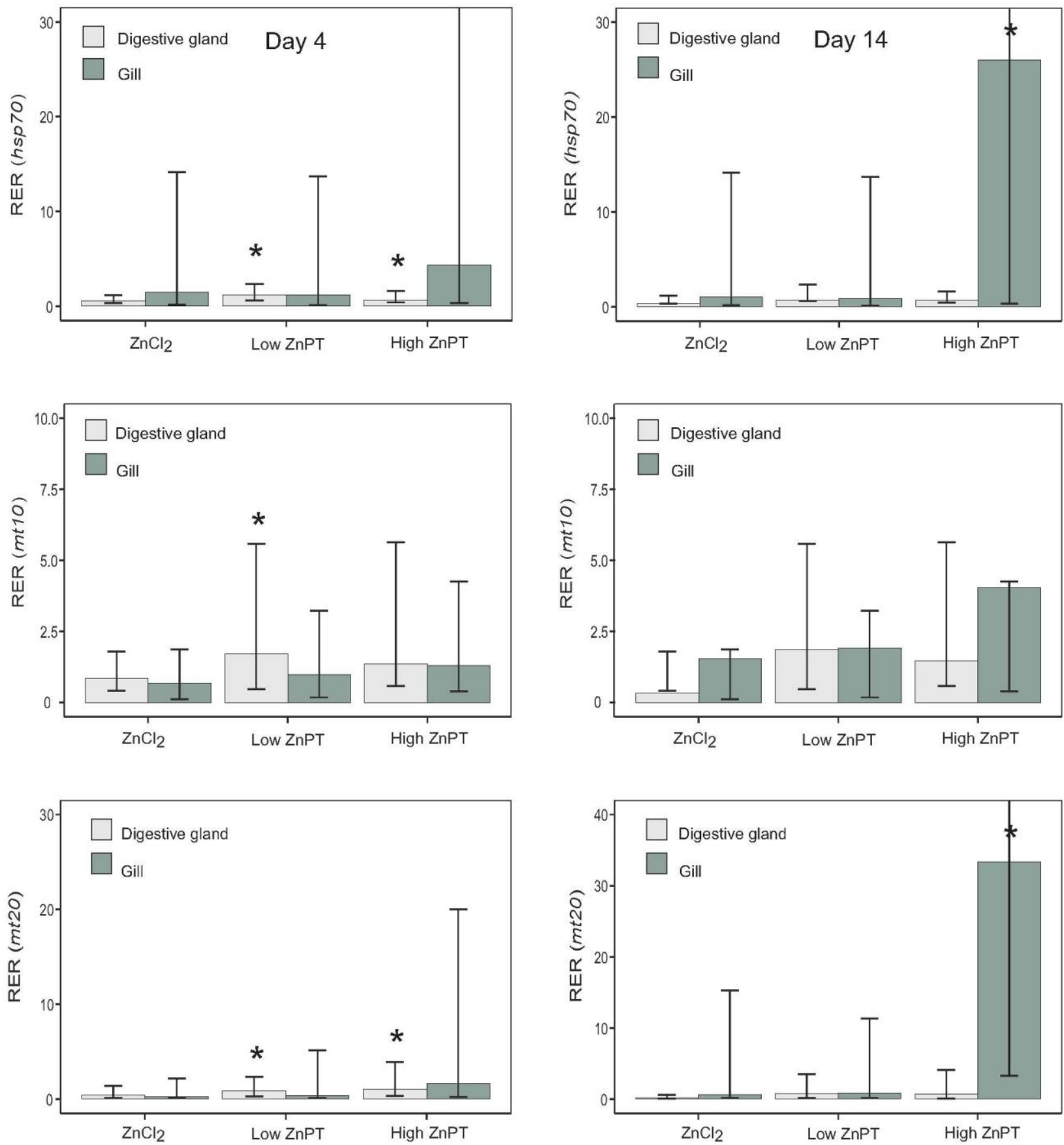

815

816 Figure 3: Relative expression ratios (RER) of three genes ( $h s p 70, m t 10$ and $m t 20$ ) in

817 digestive gland and gill tissue of $M$. galloprovincialis after exposure to inorganic $\mathrm{Zn}$ or

818 ZnPT. Data are normalised for two reference genes (atub and ef1) and the sea water

819 control treatment and are shown with $\pm 95 \%$ confidence intervals. Values above 1

820 indicate upregulation and those below downregulation. Significant differences

821 (PFRRT, $p<0.05)$ from the corresponding tissue control at day 0 are indicated by

822 asterisks. 

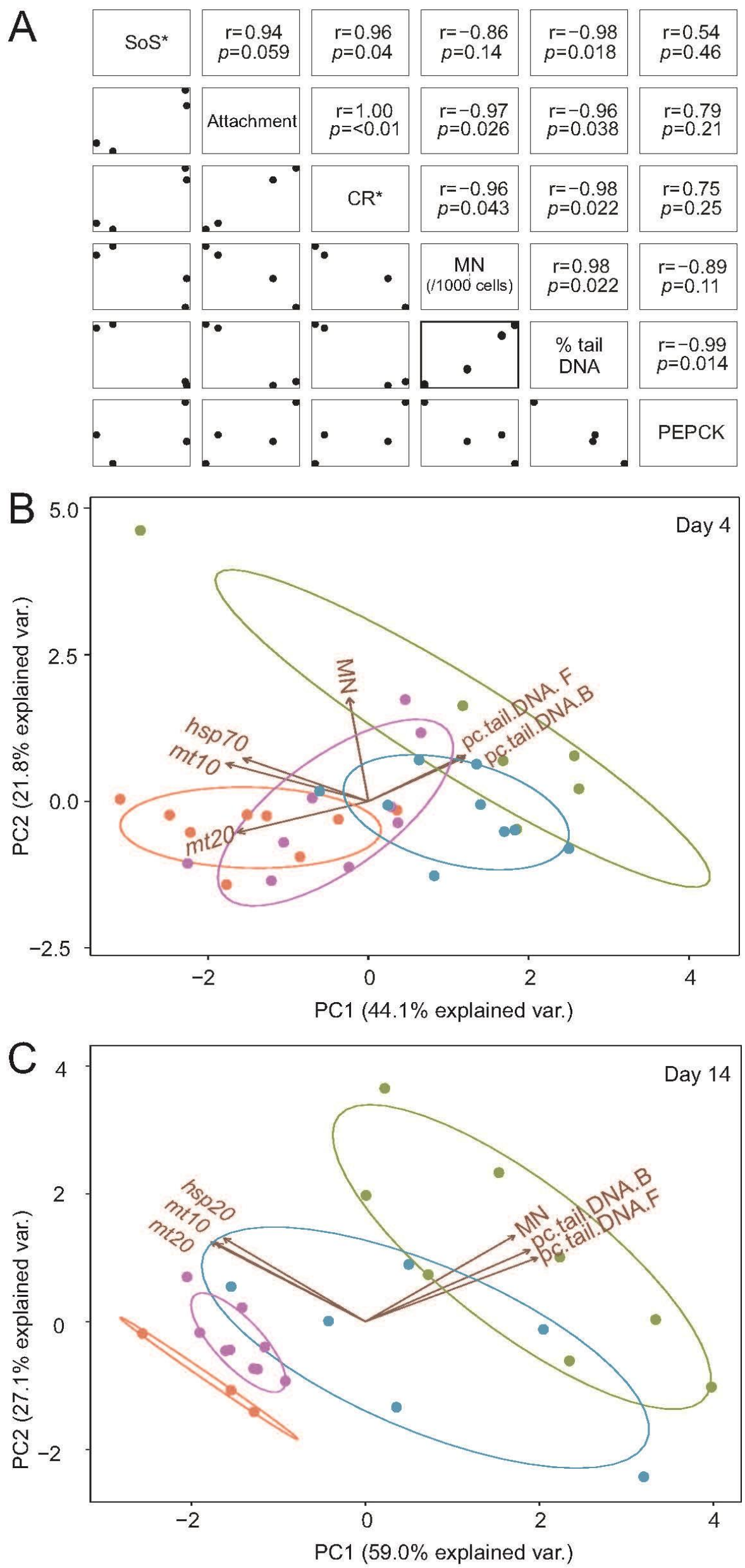
824 Figure 4: Links between responses at different levels of biological organisation in $M$. 825 galloprovincialis across all treatments. (A) Correlation matrix showing relationships 826 between higher level responses, genotoxicity and expression of PEPCK. Data were 827 averaged for each treatment and parameters were measured from day 14 onwards 828 except where noted with an asterisk, with lower left panels showing data plots and 829 upper diagonal panels showing corresponding $r$ and $p$ values. (B) and (C) Principal 830 component analysis of 6 genotoxicity and gene expression parameters $\left(\Delta C_{q}\right.$ values 831 for $h s p 70, m t 20$ and $m t 10$, \% tail DNA [buffer], \% tail DNA [Fpg] and MN/1000 cells) 832 for 4 and $14 \mathrm{~d}$, respectively. 
833 Table 1: Differentially expressed proteins in the digestive gland of $M$.

834 galloprovincialis exposed to 0.2 or $2 \mu \mathrm{M} \mathrm{ZnPT}$ for $4 \mathrm{~d}$. Non-significant fold changes

$835 \quad(p>0.05)$ have been omitted.

836

837

Spot id protein id

Fold change relative to

Fold change relative to

838

839

840

841

239

$0.2 \mu \mathrm{M}$

$2 \mu \mathrm{M}$ inorganic $\mathrm{Zn}$

$842 \quad 355$

unidentified

$+2.10$

$0.2 \mu \mathrm{M}$

$2 \mu \mathrm{M}$

843

$844 \quad 412$

phosphoenolpyruvate

$+1.89$

$845 \quad 550$

carboxykinase

$846 \quad 607$

unidentified

$-1.68$

$-2.04$

$-1.73$

$-2.10$

small heat shock $24.1+1.78$

$+1.90$

847

848

849

850

851

852

853

854

855

856

857

858

859

860

861

862 